\title{
Personality and the physician-patient relationship as predictors of quality of life of cardiac patients after rehabilitation
}

\author{
Erik Farin*, Milena Meder
}

\begin{abstract}
Background: Numerous studies document the influence of psychosocial variables on the course of coronary heart disease. This study examines the influence of personality traits (trait anger, cynicism) and aspects of the physicianpatient relationship (promoting patient participation by the physician, active communication behavior of the patient, trust in the physician) on the health related quality of life (HRQOL) of cardiac patients after rehabilitation.

Methods: $N=331$ patients with chronic ischemic heart disease were surveyed using questionnaires at two time points (beginning and end of 3-weeks inpatient rehabilitation). In addition, characteristics of the disease and cardiac risk factors were provided by the physician. HRQOL was measured using a total of six scales and three instruments: SF-12, MacNew questionnaire, and SAQ. Hierarchical regression analyses were carried out to predict $\mathrm{HRQOL}$ after rehabilitation, in which the baseline values of HRQOL, sociodemographic variables, characteristics of the disease and risk factors, personality traits, and finally the aspects of the physician-patient relationship were included stepwise. As a number of variables were used for the regression models, multiple imputation was conducted.

Results: The baseline values explain most of the variance (42\%-60\%). After controlling the baseline values, the sociodemographic variables explain up to $5 \%$ incremental variance of $\mathrm{HRQOL}$, with income being the most important predictor. The characteristics of the disease and cardiac risk factors explain between $0.4 \%$ and $3.8 \%$ incremental variance, however, variance increase is often not significant. The personality traits added in the fourth step explain up to $2 \%$ additional variance; trait anger is a significant predictor of $\mathrm{HRQOL}$ in three of the six scales. The features of the physician-patient relationship included in the last step lead to a significant increase in explained variance (between 1.3\% and 3.9\%) for all six scales. In particular, the physician's promotion of patient participation has a significant influence. The overall explanation of variance for HRQOL is between 50\% and 64\%.

Conclusions: Low income, a high level of trait anger, and low patient participation are significant risk factors, even if a number of potential confounders are adjusted. Research is needed that shows which causal pathway low income functions on and what therapies in rehabilitation can mitigate the disadvantage of persons with a high level of trait anger. The providers should implement measures to actively integrate rehabilitation patients in treatment (e.g. encourage them to ask questions).
\end{abstract}

\section{Introduction}

There is extensive empirical evidence that psychological and psychosocial characteristics have an influence on the incidence and prognosis of coronary heart disease (CHD) (e.g. $[1,2])$. Additionally, the influence of psychosocial

\footnotetext{
* Correspondence: erik.farin@uniklinik-freiburg.de

University Medical Center Freiburg, Dept. of Quality Management and Social Medicine, Breisacher Str. 62/Haus 4 D-79106, Freiburg, Germany
}

variables on risk factors for CHD such as hypertension, smoking behavior, serum cholesterol, and body mass index has been shown [3-6]. Among the psychological characteristics most frequently discussed in this context are the personality characteristics anger and cynicism.

With reference to Spielberger's State-Trait Anger Expression Inventory (STAXI) [7] and the concept of anger on which this instrument is based, a differentiation is frequently made between trait anger, anger 
expression, and anger suppression. Trait anger is considered a personality trait characterized by the fact that the person perceives many situations as annoying and thus experiences frequent, intense anger [8]. Studies that have examined the influence of trait anger come to the conclusion that even after adjusting standard risk factors such as age, race, body mass index, education, and smoking, a correlation with carotid artery atherosclerosis $[9,10]$ or high blood pressure [3] can be proven.

Cynicism can be considered the cognitive component of the multidimensional construct "hostility" [11,12]. The construct includes negative beliefs about human nature and the belief that others are potentially threatening antagonists, who frequently have negative intentions and should thus be met with caution and distrust. Anger and cynicism are viewed as independent risk factors for CHD, however, they are related, as anger can also be considered an affective component of hostility $[11,13]$. Studies have shown that cynicism or closely related concepts such as hostile attributions are predictors of mortality in patients with CHD [14] and are associated with a higher probability of the occurrence of adverse events (e.g. hospitalization for angina, nonfatal myocardial infarction) [15]. In the normal population as well, cynicism appears to be associated with an increased risk of incident myocardial infarction (cf. [16]), however, there are also studies that find no correlation after adjusting for relevant risk factors [17]. Many studies examine either anger or cynicism; some (such as [18]) analyze the influence of both variables in parallel.

When examining the relevance of anger and cynicism, the primary focus was on mortality, the incidence of new cardiac diseases, or the occurrence of impaired body functions. Health-related quality of life (HRQOL) or other patient-reported outcomes were given less consideration, although improving or maintaining HRQOL is very important for chronic cardiac patients and - particularly in the rehabilitation phase - is an important treatment goal (cf. $[19,20])$. Julkunen and Ahlström [21] found in a large sample of patients with an increased risk of cardiovascular disease that cynicism and anger correlate with HRQOL. The impact of cynicism and anger was, to a great extent, mediated through sense of coherence. A few sociodemographic variables were considered as confounding factors, but not body function parameters or other cardiac risk factors. In a series of studies [22,23], Shen et al. developed prognosis models for predicting the HRQOL of cardiac patients following rehabilitation and they come to the conclusion that hostility affects HRQOL directly and indirectly through depression. However, in the two studies mentioned, anger was not taken into consideration.

Since the personality variables anger and cynicism (especially the latter) have a direct effect on the form of social interaction, it can be expected that they have a correlation to the quality of the physician-patient relationship. However, we are not aware of any study that has examined both the influence of these personality variables and the influence of the physician-patient relationship on the HRQOL of CHD patients after rehabilitation. Of the studies mentioned above, only the studies by Shen et al. [22,23] study rehabilitation care; the authors examine patients in outpatient rehabilitation.

While research groups that have dealt with the influence of anger and cynicism on cardiac disease are frequently based in behavioral medicine or psychosomatic medicine, there are studies on the significance of physician-patient communication from the field of provider-patient research. These studies show that aspects of the physician-patient relationship such as involving the patient in decision-making processes [24,25], positive assessment of communication and interaction by the patient [26,27], and patient's trust in the physician [28] affect not only adherence, but the patient-reported outcome of treatment as well.

The objective of our study is to address elements of these two research traditions in parallel. We examine two hypotheses:

1. Even after adjusting for relevant sociodemographic characteristics, characteristics of the CHD (including risk factors), and the HRQOL at the beginning of inpatient rehabilitation, the personality traits cynicism and anger correlate with the HRQOL after rehabilitation.

2. Even after adjusting for relevant sociodemographic characteristics, characteristics of the CHD (including risk factors), the HRQOL at the beginning of inpatient rehabilitation, and the personality traits cynicism und anger, aspects of the physicianpatient relationship perceived by the patient correlate with the HRQOL after rehabilitation.

Through statistical controlling for HRQOL at the beginning of rehabilitation, it is examined whether the personality traits and the physician-patient relationship allow the improvements in the HRQOL that can be achieved by inpatient rehabilitation to be predicted. According to the findings available in literature on confounding influence factors for CHD patients (e.g. [29-33]) age, gender, living with a partner, education, employment, and income will be regarded as sociodemographic confounders. The existence of an acute event and if applicable, the kind of surgery performed before rehabilitation (PTCA, bypass) are important characteristics of the CHD. In addition, various body function parameters and risk factors will be controlled (body mass index (BMI), smoker, total cholesterol, LDL cholesterol, systolic blood pressure, diastolic blood pressure, and the risk score described by Daly [34]). Patient participation in the sense of shared decision making (SDM) [35] and trust in the physician are considered aspects of the physician-patient relationship. 


\section{Methods}

\section{Sample}

The study has been approved by the ethics committee of the University Freiburg (approval number 63/08). Patients with chronic ischemic heart disease who were undergoing inpatient rehabilitation were surveyed. In Germany, inpatient cardiac rehabilitation aims at achieving the best possible regeneration of the patient's cardiac capacities with respect to all psychosocial aspects in order to re-integrate the patient into social and working life [36]. The goals of inpatient rehabilitation are similar to those of outpatient rehabilitation, but patients in inpatient rehabilitation are likely to be older, less mobile, and less often employed [36]. Cardiac rehabilitation is a multidisciplinary activity. Besides physicians, the rehabilitation team includes psychologists, nursing staff, exercise therapists, physiotherapists, nutrionists and social workers. The patient generally has 4-5 therapy sessions a day on workdays. Rounds and consultations with the physician take place at least once a week, with additional consultations by appointment. Normally, there is a physician responsible for the patient who sees him frequently during the hospitalization period. Depending on the situation and extent of medical care required, the patient may have contact with other physicians.

The patient questionnaires were given only to patients who were able and willing to fill out the questionnaires (informed consent). $\mathrm{N}=742$ patients were asked to participate, $\mathrm{N}=331$ agreed. The percentage of patients that did not fill out the questionnaire (decliners) was $55.4 \%$. The most important reason for non-inclusion was refusal to participate $(46.4 \%)$, followed by cognitive or physical limitations (13.0\%) and language problems (6.5\%). For $34.2 \%$ of the patients no reason for noninclusion was reported. Table 1 provides information on the patients in the study.

\section{Instruments}

At the beginning and end of the inpatient rehabilitation lasting an average of $21(+/-3.1)$ days, the patients were asked to fill out a questionnaire that, in addition to sociodemographic information, included the SF-12 [37] (scales: physical component $\mathrm{PC}$ and mental component $\mathrm{MC}$ ), MacNew [38] (scales: physical limitation PL, emotional functioning EF, social functioning SF), Seattle Angina Questionnaire SAQ [39] (scale considered here: physical limitation PL), Perceived Involvement in Care Scales PICS [40] (scales: doctor facilitation DF, patient information PI), Trust in Physician [41], MMPI-2 scale cynicism [42], and STAXI scale trait anger [7]. Several instruments for quality of life were implemented in parallel to enable statements about the method-related variance. The rehabilitation physicians filled out a documentation sheet at the beginning
Table 1 Respondent characteristics

\begin{tabular}{lc}
\hline \hline Average age (SD) & $61.1(10.9)$ \\
\hline Gender & \\
\% of men & 82.4 \\
\hline Level of education (highest level Completed) & 52.6 \\
\hline \% elementary school & \\
\hline Employment & 41.0 \\
\% employed & \\
\hline Monthly household income (\%) & 4.0 \\
< 500 Euro & 10.0 \\
500 -1.000 Euro & 23.3 \\
1.000 - 1.500 Euro & 24.1 \\
1.500 - 2.000 Euro & 19.3 \\
2.000 - 2.500 Euro & 7.2 \\
2.500 - 3.000 Euro & 5.2 \\
3.000 - 3.500 Euro & 6.8 \\
> 3.500 Euro & \\
\hline Acute event/surgery & 65.7 \\
\% Myocardial infarction & 62.3 \\
\% PTCA & 34.7 \\
\% Bypass & \\
(Multiple choices possible) & 45.7 \\
\hline Chronification (\%) & 29.0 \\
Acute event & 6.1 \\
< 1 year & 6.5 \\
1-2 years & 4.1 \\
6-10 years & 7.2 \\
> 10 years & \\
\hline & \\
\hline & \\
\hline
\end{tabular}

and end of rehabilitation that covered mainly characteristics of the disease and cardiac risk factors.

For the study reported here, the respective German language versions were used, which are available for all instruments and whose psychometric quality criteria have already been tested in various studies and were found to be satisfactory to good overall (cf. e.g. [43,44] for the HRQOL instruments).

\section{Analyses}

\section{Multiple imputation}

Since we conduct regression analyses with a large number of predictors that all have a certain percentage of missing values, a method using casewise deletion would have many disadvantages (cf. [45]). Therefore, multiple imputation [46] was used. First, all persons with more than 50\% missing values (cf. [45]) were eliminated from the data set. This reduced the data set to $\mathrm{N}=319$ cases. Then five imputed data sets were created using NORM software [47] according to the recommendations of Rubin [46]. An expectation-maximization algorithm and 
the data augmentation procedure integrated in the NORM software were applied. We examine the convergence behavior with NORM's plotting procedure. The plots show rapidy coverging series and low autocorrelation. The analyses presented in the results section were carried out with all five imputed data sets. The relevant parameters (regression coefficients, standard errors, etc.) were combined according to the rules presented by Rubin [46].

\section{Regression analyses}

Hierarchical regression analyses were performed, in which first the baseline values with respect to the respective dependent variables (HRQOL scales) were included. In the second block, all confounding sociodemographic variables that were listed in the introduction were added, in the third step characteristics of the CHD, body function parameters, and risk factors, and in the fourth block, the personality variables (cynicism and anger). Finally, in the fifth step, the characteristics of physician-patient relationship perceived by the patient were included. A stepwise method of variable inclusion (PIN $=.05$ POUT $=.10)$ was employed. The predictors that were included in the model in at least two of the five imputed data sets were considered as potentially relevant predictors. With this restriction, more sparse models could be specified and problems of multicollinearity avoided. A separate model was specified for each of the six dependent variables (two SF-12 scales, three MacNew scales, one SAQ scale). Finally, the regression models that consisted only of potentially relevant predictors were again applied to all five imputed sets. Here again, hierarchical regression analyses were computed, but now using the forced entry method of variable inclusion, making the results in the five imputed data sets directly comparable. For the diagnosis of multicollinearity, the variance inflation factor (VIF) was calculated. Values over 5 can be considered as an indication of multicollinearity [48]. Statistical analyses were performed using SPSS 17.0 [49].

\section{Results}

Table 2 shows descriptive statistics for the HRQOL scales, the personality variables and the characteristics of physician-patient relationship. For the HRQOL scales, the table also shows the effect sizes of the change after rehabilitation (difference of the mean values divided by the pretest standard deviation); the values are .22 to .57, in the range of low to moderate effects (cf. [50]).

Before addressing the results of the multivariate analyses, the bivariate correlations between the dependent variables analyzed and all the respective potentially relevant predictors are shown in Table 3 . It can be seen that the baseline value always had the greatest correlation with the HRQOL value after inpatient rehabilitation. For the sociodemographic variables, income had the greatest correlation with HRQOL after rehabilitation and for medical variables, the risk score. Both the personality variables and the aspects of the physician-patient relationship correlate significantly with the HRQOL on various scales.

Table 4 presents the results of the hierarchical regression analyses. The values of the VIF are generally below 2 and always below 5 , so there is no indication of high multicollinearity. The baseline values explain between $42.0 \%$ and $59.4 \%$ of the variance of the HRQOL values after rehabilitation. The sociodemographic variables show significant incremental explanation of variance on all HRQOL scales. The additional explained variance ranges between $0.7 \%$ and $5.0 \%$. The most significant sociodemographic variable is - just as for the univariate analyses - income, and the influence of income on emotional and mental aspects of the HRQOL is even clearer. Even taking all confounders mentioned here into consideration, persons with higher incomes also indicate a higher psychological HRQOL at follow-up; i.e., they appear to benefit more from rehabilitation.

The characteristics of the CHD and the risk factors explain only little incremental variance beyond the sociodemographic variables. The amount ranges between $0.4 \%$ and $3.8 \%$ and is often not significantly different from zero. The most important predictor variable within this block of variables is the cardiac risk score, which is particularly significant with respect to the physical component of HRQOL. Persons with a higher risk score, that is with a higher probability for death or myocardial infarction, have a lower HRQOL after rehabilitation, i.e. they benefit less from rehabilitation with respect to HRQOL.

On all three psychosocial scales and on the "physical limitation" scale of the MacNew questionnaire, the two personality variables trait anger and cynicism together explain a significant portion of incremental variance, which is albeit not too high (between $0 \%$ and $2.0 \%$ ). For the psychosocial HRQOL, trait anger appears to be more important than cynicism. Persons who tend to be angry in many situations have a lower HRQOL after rehabilitation, even after adjusting for sociodemographic variables, characteristics of the CHD, and risk factors. Cynicism also proves to be a relevant risk factor for one of the HRQOL constructs - the physical limitation measured by the SAQ is less favorable if the person exhibits negative and cynical attitudes.

In the last step, after the baseline HRQOL values and after sociodemographic, medical, and personality variables, aspects of the physician-patient relationship perceived by the patient were included in the regression model. Although there were thus strict conditions for achieving additional explanation of variance, the aspects 
Table 2 Descriptive statistics

\begin{tabular}{|c|c|c|c|c|c|}
\hline & Minimum in dataset & Maximum in dataset & Mean & Standard deviation & Effect size (for HRQOL scales) \\
\hline \multicolumn{6}{|l|}{ HRQOL } \\
\hline \multicolumn{6}{|l|}{ SF-12: PC } \\
\hline Start of rehabilitation & 8,47 & 58,51 & 34,09 & 10,29 & .32 \\
\hline End of rehabilitation & 7,51 & 65,11 & 37,34 & 10,87 & \\
\hline \multicolumn{6}{|l|}{ MacNew: PL } \\
\hline Start of rehabilitation & 1.60 & 7 & 4.69 & 1.22 & .46 \\
\hline End of rehabilitation & 1,99 & 7 & 5,25 & 1,10 & \\
\hline \multicolumn{6}{|l|}{ SAQ: PL } \\
\hline Start of rehabilitation & 0 & 100 & 56,35 & 25,29 & .22 \\
\hline End of rehabilitation & 0 & 100 & 61,85 & 24,78 & \\
\hline \multicolumn{6}{|l|}{ SF-12: MC } \\
\hline Start of rehabilitation & 9,84 & 70,14 & 46,39 & 12,18 & .39 \\
\hline End of rehabilitation & 11,81 & 75,37 & 51,09 & 11,60 & \\
\hline \multicolumn{6}{|l|}{ MacNew: EF } \\
\hline Start of rehabilitation & 1,17 & 7 & 4,79 & 1,24 & .47 \\
\hline End of rehabilitation & 1,33 & 7 & 5,37 & 1,13 & \\
\hline \multicolumn{6}{|l|}{ MacNew: SF } \\
\hline Start of rehabilitation & 1,18 & 7 & 4,56 & 1,33 & .57 \\
\hline End of rehabilitation & 1,80 & 7 & 5,32 & 1,14 & \\
\hline \multicolumn{6}{|l|}{ Personality variables } \\
\hline Cynicism & 0 & 23 & 12,63 & 5,17 & \\
\hline Trait anger & 10 & 37 & 18,24 & 5,01 & \\
\hline \multicolumn{6}{|c|}{ Physician patient relationship } \\
\hline PICS: DF & 1 & 4 & 2,94 & 0,72 & \\
\hline PICS: PI & 1 & 4 & 3,01 & 0,75 & \\
\hline Trust in physician & 25,90 & 100 & 79,58 & 14,44 & \\
\hline
\end{tabular}

Personality variables were measured at the beginning of rehabilitation, variables of the physician-patient relationship at the end of rehabilitation. For all HRQOL scales, higher values indicate higher quality of life. Effect size $=$ difference of the mean values divided by the pretest standard deviation.

led to a significant increase in explained variance for all six HRQOL scales. The amount fluctuated between $1.3 \%$ and $2.9 \%$ and is thus generally greater than the increase in explanation of variance by the characteristics of the disease. The relevance of this block of variables is mainly due to the doctor facilitation scale of the PICS: patients who experienced the physician as a provider who attempted to include the patient in the treatment (e.g. asked the patient for consent; asked the patient what he considered to be the causes of his condition; encouraged the patient to give his opinion), had a higher quality of life at the end of rehabilitation than patients who experienced a patriarchal style of interaction. Trust in the physician was only occasionally a significant predictor in the multivariate analyses; the patient's active communication behavior (patient information scale of the PICS) does not appear to be relevant.

\section{Discussion}

The two hypotheses presented in the introduction were confirmed, at least for some of the sub-dimensions. The relevance of the personality variables was shown in particular for the psychosocial aspects of the HRQOL, while the aspects of the physician-patient relationship are important for all domains of the HRQOL. The confirmation of the significance of anger and cynicism is compatible with existing studies [21-23], and it should be mentioned as a strength of our study that a number of disease characteristics and body function parameters were controlled and that the HRQOL was measured using various instruments. It was seen that the disease characteristics are generally less significant, with the exception of the risk score as a measure of the severity of the illness. While the differences between the various HRQOL scales are considerable for individual predictors, the fundamental relevance of the personality variables and the physician-patient relationship was seen to be independent of whether the SF-12, the MacNew questionnaire, or the SAQ was used.

Our data also show the relevance of income for the improvement of the psychological quality of life. After the baseline value, income was the most important 
Table 3 Bivariate correlations between dependent variables and respective predictors

\begin{tabular}{|c|c|c|c|c|c|c|}
\hline & $\begin{array}{l}\text { SF-12: } \\
\text { PC }\end{array}$ & $\begin{array}{c}\text { MacNew: } \\
\text { PL }\end{array}$ & SAQ: PL & $\begin{array}{l}\text { SF-12: } \\
\text { MC }\end{array}$ & $\begin{array}{c}\text { MacNew: } \\
\text { EF }\end{array}$ & $\begin{array}{l}\text { MacNew: } \\
\text { SF }\end{array}$ \\
\hline Respective base-line value (at start of rehabilitation) & $.661^{* * *}$ & $.700^{* * *}$ & $.707^{* * *}$ & $.649^{* * *}$ & $.772^{* * *}$ & $.700^{* * *}$ \\
\hline Age & $-.220^{* * *}$ & - & - & .087 & $.146^{*}$ & - \\
\hline Gender: man & $.179 *$ & - & - & $.188^{* *}$ & .095 & - \\
\hline Living with a Partner & - & - & - & - & - & - \\
\hline Education: Elementary School & -.131 & -.095 & - & - & -.051 & -.048 \\
\hline Employment & - & - & $.274^{* * *}$ & - & - & - \\
\hline Income & - & $.273^{* * *}$ & - & $.243^{* * *}$ & $.222^{* * *}$ & $.198^{* *}$ \\
\hline Acute event & - & - & - & - & - & - \\
\hline Myocardial Infarction & - & - & - & - & - & - \\
\hline PTCA & $.291^{* * *}$ & - & - & - & - & - \\
\hline Bypass & - & - & $-.360^{* * *}$ & .016 & - & - \\
\hline BMI & - & - & - & -.021 & - & - \\
\hline Smoker & .087 & - & - & - & - & - \\
\hline Risk score & -.116 & $-.216^{* * *}$ & $-.219^{* * *}$ & - & - & $-.198 * *$ \\
\hline Total cholesterol & - & - & .080 & - & -.044 & - \\
\hline LDL cholesterol & - & - & $.115^{*}$ & - & - & - \\
\hline Systolic blood Pressure & - & - & - & -.025 & - & - \\
\hline Diastolic blood Pressure & - & - & - & - & - & - \\
\hline Cynicism & - & $-.212^{* *}$ & $-.186^{* *}$ & - & - & - \\
\hline Trait anger & - & $-.231^{* * *}$ & - & $-.325^{* * *}$ & $-.377^{* * *}$ & $-.277^{* * *}$ \\
\hline PICS: DF & .084 & $.162^{* *}$ & .109 & .080 & $.151^{* *}$ & .103 \\
\hline PICS: PI & -.013 & .013 & - & -.085 & - & -.030 \\
\hline Trust in Physician & - & - & - & $.208^{*}$ & $.290^{* * *}$ & $.197^{* * *}$ \\
\hline
\end{tabular}

Pearson correlations with significance level, ${ }^{* * *} p<.001,{ }^{* *} p<.01,{ }^{*} p<.05,-=$ not in the model

predictor variable for the SF-12-MC as well as the MacNew-EF. Literature reports on socioeconomic status (SES) as a moderator of the correlation between anger and subclinical atherosclerosis for members of the general population (cf. [11]) and occasionally income is also adjusted (cf. [4]), but we are not aware of any study that has examined personality variables and SES in parallel for the prediction of the HRQOL after cardiac rehabilitation. Studies that examine influence factors of the outcome of cardiac rehabilitation independently of personality variables occasionally also indicate the influence of the SES (e.g. [30]), however, there was not always a clear distinction made between education and income (cf. [31]). Our data indicate that low income and low education level are separate risk factors, whereas only income is an influence factor of the psychological HRQOL. Corresponding with this finding, in our sample there is only a slight correlation between the two variables $(r=0.28)$. The significance of SES for the
HRQOL in the context of cardiac rehabilitation is not surprising, although there has thus far been little proof, as social inequality in cardiovascular diseases has been studied on several occasions and correlations have been found, for example with heart disease mortality [51].

In the analysis of the influence of the physicianpatient relationship on the HRQOL, the physician's inclusion of the patient in treatment planning proved to be a significant conducive factor for the physical and social HRQOL. This finding made in a prospective study does not reach the level of evidence of a randomized controlled trial, but since an extensive control of potential confounders was made and patient participation was not included until the last block of the model, it does appear to us to be an argument for the importance of patient-oriented communication style and for the relevance of the SDM concept. The results are compatible with intervention studies (e.g. $[52,53])$ and observation studies [54], which show that for cardiac disease, 
Table 4 Hierarchical regression analyses to predict HRQOL at the end of rehabilitation

\begin{tabular}{|c|c|c|c|c|c|c|}
\hline & SF-12: PC & MacNew: PL & SAQ: PL & SF-12: MC & MacNew: EF & MacNew: SF \\
\hline \multicolumn{7}{|l|}{ Block 1} \\
\hline \multirow{2}{*}{$\begin{array}{l}\text { Respective baseline value (at start of } \\
\text { rehabilitation) }\end{array}$} & $.631(p<.001)$ & $.613(p<.001)$ & $.605(p<.001)$ & $.582(p<.001)$ & $.723(p<.001)$ & $.633(p<.001)$ \\
\hline & $\begin{array}{l}\mathrm{R}^{2} \text { change }= \\
.436^{* * *}\end{array}$ & $\begin{array}{l}R^{2} \text { change }= \\
.488^{* * *}\end{array}$ & $\begin{array}{l}\mathrm{R}^{2} \text { change }= \\
.498^{* * *}\end{array}$ & $\begin{array}{l}\mathrm{R}^{2} \text { change }= \\
.420^{* * *}\end{array}$ & $\begin{array}{l}\mathrm{R}^{2} \text { change }= \\
.594^{* * *}\end{array}$ & 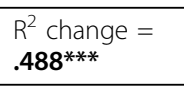 \\
\hline \multicolumn{7}{|l|}{ Block 2} \\
\hline Age & $-.112(p=.050)$ & - & - & $.090(p=.105)$ & $.087(p=.049)$ & - \\
\hline Gender: man & $.083(p=.105)$ & - & - & $.079(p=.083)$ & $-.084(p=.029)$ & - \\
\hline Living with a partner & - & - & - & - & - & - \\
\hline Education: elementary school & $-.151(p=.002)$ & $-.057(p=.214)$ & - & - & $-.034(p=.436)$ & $-.058(p=.226)$ \\
\hline Employment & - & - & $.070(p=.113)$ & - & - & - \\
\hline \multirow[t]{2}{*}{ Income } & - & $.082(p=.149)$ & - & $.151(p=.013)$ & $.119(p=.004)$ & $.088(p=.106)$ \\
\hline & $\begin{array}{l}R^{2} \text { change }= \\
.050^{* * *}\end{array}$ & $\begin{array}{l}R^{2} \text { change }= \\
.011^{*}\end{array}$ & $\begin{array}{l}R^{2} \text { change }= \\
.007^{*}\end{array}$ & $\begin{array}{l}R^{2} \text { change }= \\
.037^{*}\end{array}$ & $\begin{array}{l}R^{2} \text { change }= \\
.023^{* *}\end{array}$ & $\begin{array}{l}R^{2} \text { change }= \\
.013^{*}\end{array}$ \\
\hline \multicolumn{7}{|l|}{ Block 3} \\
\hline Acute event & - & - & - & - & - & - \\
\hline Myocardial infarction & - & - & - & - & - & - \\
\hline PTCA & $.139(p=.042)$ & - & - & - & - & - \\
\hline Bypass & - & - & $-.139(p=.003)$ & $.049(p=.347)$ & - & - \\
\hline BMl & - & - & - & $.074(p=.133)$ & - & - \\
\hline Smoker & $-.082(p=.280)$ & - & - & - & - & - \\
\hline Risk score & $-.055(p=.350)$ & $-.113(p=.017)$ & $-.123(p=.016)$ & - & - & $-.103(p=.067)$ \\
\hline Total cholesterol & - & - & $.114(p=.392)$ & - & $.074(p=.044)$ & - \\
\hline LDL cholesterol & - & - & $.028(p=.746)$ & - & - & - \\
\hline Systolic blood pressure & - & - & - & $.067(p=.369)$ & - & - \\
\hline \multirow[t]{2}{*}{ Diastolic blood pressure } & - & - & - & - & - & - \\
\hline & $\begin{array}{l}R^{2} \text { change }= \\
.024^{* *}\end{array}$ & $\begin{array}{l}\mathrm{R}^{2} \text { change }= \\
.004\end{array}$ & $\begin{array}{l}R^{2} \text { change }= \\
.038^{* *}\end{array}$ & $\begin{array}{l}\mathrm{R}^{2} \text { change }= \\
.010\end{array}$ & $\begin{array}{l}R^{2} \text { change }= \\
.005^{*}\end{array}$ & $\begin{array}{l}R^{2} \text { change }= \\
.005\end{array}$ \\
\hline \multicolumn{7}{|l|}{ Block 4} \\
\hline Cynicism & - & $-.077(p=.219)$ & $-.108(p=.033)$ & - & - & - \\
\hline \multirow[t]{3}{*}{ Trait anger } & - & $-.095(p=.028)$ & - & $-.118(p=.091)$ & $-.080(p=.032)$ & $-.144(p<.001$ \\
\hline & $\begin{array}{l}\mathrm{R}^{2} \text { change }= \\
.000\end{array}$ & $\begin{array}{l}\mathrm{R}^{2} \text { change }= \\
.015^{* *}\end{array}$ & $\begin{array}{l}R^{2} \text { change }= \\
.006\end{array}$ & $\begin{array}{l}\mathrm{R}^{2} \text { change }= \\
.013^{* *}\end{array}$ & $\begin{array}{l}R^{2} \text { change }= \\
.006^{* *}\end{array}$ & $\begin{array}{l}\mathrm{R}^{2} \text { change }= \\
.020^{* * *}\end{array}$ \\
\hline & SF-12: PC & MacNew: PL & SAQ: PL & SF-12: MC & MacNew: EF & Mac New:SF \\
\hline \multicolumn{7}{|l|}{ Block 5} \\
\hline PICS: DF & $.130(p=.049)$ & $\begin{array}{l}.220(p=< \\
.001)\end{array}$ & $.130(p=.004)$ & $.099(p=.357)$ & $.069(p=.148)$ & $.132(p=.025$ \\
\hline PICS: PI & $-.127(p=.187)$ & $-.089(p=.276)$ & $-.123(p=.076)$ & - & & $-.101(p=183$ \\
\hline \multirow[t]{2}{*}{ Trust in physician } & - & - & - & $.095(p=.086)$ & $.087(p=.046)$ & $.052(p=.384)$ \\
\hline & $\begin{array}{l}R^{2} \text { change }= \\
.013^{*}\end{array}$ & $\begin{array}{l}R^{2} \text { change }= \\
.029^{* * *}\end{array}$ & $\begin{array}{l}R^{2} \text { change }= \\
.015^{* *}\end{array}$ & $\begin{array}{l}\mathrm{R}^{2} \text { change }= \\
.022^{* *}\end{array}$ & $\begin{array}{l}\mathrm{R}^{2} \text { change }= \\
.017^{* *}\end{array}$ & $\begin{array}{l}\mathrm{R}^{2} \text { Change }= \\
.016^{* *}\end{array}$ \\
\hline$\overline{R^{2}}$ & .523 & .547 & .563 & .503 & .645 & .542 \\
\hline
\end{tabular}

Standardized regression coefficients and $\mathrm{R}^{2}$ change with significance, ${ }^{* * *} \mathrm{p}<.001,{ }^{* *} \mathrm{p}<.01,{ }^{*} \mathrm{p}<.05,-=$ not in the model. Significant parameters ( $\left.\mathrm{p}<.05\right)$ are printed in bold type. 
including the patient in the decision-making process leads to a positive effect on the treatment outcome. However, on the basis of our data we cannot make any statements about the causal path that ultimately leads from the physician's interaction style to an improvement in the HRQOL. A mediator function of therapy adherence is conceivable [55].

It was surprising that active patient communication aimed at participation (e.g. asking physicians to explain treatment in more detail; asking physicians about symptoms of the illness) did not have a significant influence on any HRQOL scale. This was in contrast to studies that show that patient participation can be improved with comparably easy-to-conduct patient communication trainings (cf. [56,57]). It is possible that, without intervention, the influence of proactive patient behavior is too weak to influence the treatment process and thus the HRQOL at the end of treatment. The only slight significance of trust in the physician leads to the assumption that the decisive factor influencing the physician-patient relationship for the cardiac patients studied here is not so much the quality of the emotional relationship as it is the physician's function in activating the patient and emphasizing his own responsibility. The assumption that the meager influence of trust in the physician is based on ceiling effects that are known from patient satisfaction research [58] was not confirmed; the Trust-in-Physician questionnaire has good distribution properties (data not presented in the results section).

The relevance of income for HRQOL presented above underlines the usefulness of the multiple imputation method chosen here. Since a relatively large number of missing values can be anticipated for data on income (cf. [59]; in our dataset, the percentage of missing values was $24.8 \%$ ) and a selective loss of data can be expected [60], a meaningful analysis of the relevance of income is difficult to achieve without an elaborated imputation method.

Our study has many limitations that should be addressed in closing. The relatively high decliner rate means that the patients studied cannot be considered representative for all inpatient rehabilitation patients with CHD. Since the most important reason for exclusion was refusal to participate, it is difficult to estimate what influence the high decliner rate has on the results reported here. In a comparable study [61], it was found that decliners are sicker and achieve less improvement after rehabilitation. This would presumably mean that in the group of non-participants, if the number of cases were the same, it would be more difficult to prove the relevance of the predictors studied here.

We studied two personality traits important for CHD patients in parallel, but there are other psychological constructs (e.g. depression [62,23] and sense of coherence [21]), that are closely related to anger und cynicism and possibly function as mediators or moderators. Frasure-Smith and Lésperance [63] emphasize that negative emotions (such as anger or depression) are likely to be correlated with an underlying dimension reflecting a general tendency to experience or report negative emotions, which can possibly be described as neuroticism. This means that we cannot be certain that the correlation with HRQOL found for anger and cynicism are actually only the result of these specific constructs or are perhaps also an expression of a general emotional state. If we had included other psychological variables, an approach using structural equation models to represent individual causal paths between the relevant constructs would have been promising.

It can also not be ruled out that there are other relevant predictors of HRQOL after rehabilitation that we did not cover (for example treatment motivation). It is also conceivable that activity limitations of patients at the start of rehabilitation have an influence and we can present them only to a limited extent with the medical variables and the HRQOL baseline values considered here.

With respect to anger, it should also be stressed that we studied only trait anger as a personality variable, not modes of anger expression (anger-in, anger-out, cf. [9]), which are considered aspects of affect regulation. However, this decision appears useful to us, as the patient in the rehabilitation hospital is in a special setting, so results regarding state variables are difficult to generalize.

Inclusion of the patient in the sense of SDM was measured only in relatively generally terms with the PICS scale. Newer conceptual studies (e.g. [64,65]) emphasize that the SDM construct has many factors depending on the definition; they can be only partially measured with the PICS. In addition, the PICS measures only patient perception, not the physician's assessment.

One limitation of the method is that in our analyses, we could not represent the multilevel structure of the data that stems from the fact that several patients were treated by the same physicians, as the allocation of patient to physician was not documented when the data was gathered. This aspect is relevant for the variables of the physician-patient relationship. The patient's assessments are not independent of one another for persons who have the same physician; as a result, the standard error for the linear regression is too small and correlations can be overestimated [66]. The problem is somewhat mitigated by the fact that we did not measure the objectively observable behavior of the physician, but rather the behavior assessed retrospectively by the patient. This judgment depends not only on the physician's behavior, but also on 
the cognitive system of the patient. The dependence of the judgments related to one and the same physician is thus reduced.

Finally, it should be pointed out that we used only questionnaires to measure the physician-patient relationship and not observational procedures or other qualitative methods. This leads to the problem of the common method bias (cf. e.g. [67]). Correlations between the influence factors observed here and the HRQOL could be overestimated because we used the same method to measure them. However, Doty and Glick [68] showed on the basis of published multitraitmultimethod correlation matrices that the common method bias is rarely high enough to cast a doubt on the central results of research.

\section{Conclusions}

The baseline values explain most of the variance of HRQOL after inpatient cardiac rehabilitation. HRQOL depend also on income, personality traits (especially anger), and patient-participation in treatment. These variables cover a relevant portion of the explainable variance of the HRQOL in our study. The study thus confirms findings that are reported in the existing literature mainly for the health care outcomes mortality and body function parameters. Treatment concepts in rehabilitation should include strategies that ensure the success of the intervention even for risk patients (high degree of experienced anger, low income). For providers, an interaction style is recommended that actively includes the patient in the rehabilitation and thus promotes selfmanagement in dealing with the chronic illness.

\footnotetext{
Abbreviations

BMI: body mass index; CHD: coronary heart disease; HRQOL: health-related quality of life; PICS: Perceived Involvement in Care Scales; PTCA: percutaneous transluminal coronary angioplasty; SAQ: Seattle Angina Questionnaire; SDM: shared decison making; SES: socioeconomic status; STAXI: State-Trait Anger Expression Inventory.
}

\section{Acknowledgements \\ The project from which the data reported here stem ("Patient-oriented outcome measurement: Health valuation and assessment of the relevance of the changes in patients' participation") was supported by the German Federal Ministry for Education and Research as part of the funding program "Chronic Illnesses and Patient Orientation". \\ We thank the participating rehabilitation centers and their staff: AHG Klinik Wolletzsee (Wolletz), Drei-Burgen-Klinik (Bad Münster am Stein - Ebernburg), Gesundheitszentrum Oberammergau (Oberammergau), Kerckhoff- Rehabilitations-Zentrum (Bad Nauheim), Klinik am Südpark (Bad Nauheim), Klinik Bad Wörishofen (Bad Wörishofen), Median Kliniken am Burggraben (Bad Salzuflen).}

\section{Authors' contributions}

EF analyzed the data and prepared the manuscript. MM assisted in the analysis of the data. Both authors contributed to the conception and design of the study. Both authors read and approved the final manuscript.

\section{Competing interests}

The authors declare that they have no competing interests.
Received: 15 December 2009 Accepted: 14 September 2010

Published: 14 September 2010

\section{References}

1. Rozanski A, Blumenthal JA, Kaplan J: Impact of psychological factors on the pathogenesis of cardiovascular disease and implications for therapy. Circulation 1999, 99:2192-2217.

2. Smith TW, Glazer K, Ruiz JM, Gallo LC: Hostility, anger, aggressiveness, and coronary heart disease: An interpersonal perspective on personality, emotion, and health. J Pers 2004, 72:1217-1270.

3. Schum JL, Jorgensen RS, Verhaeghen P, Sauro M, Thibodeau R: Trait anger, anger expression, and ambulatory blood pressure: a meta-analytic review. J Behav Med 2003, 26(5):395-415.

4. Rutledge T, Reis SE, Olson M, Owens J, Kelsey SF, Pepine CJ, Reichek N, Rogers WJ, Merz CN, Sopko G, Cornell CE, Matthews KA: Psychosocial variables are associated with atherosclerosis risk factors among women with chest pain: the WISE study. Psychosom Med 2001, 63(2):282-8.

5. Markovitz JH, Jonas BS, Davidson K: Psychologic factors as precursors to hypertension. Curr Hypertens Rep 2001, 3(1):25-32.

6. Goldbacher EM, Matthews KA: Are psychological characteristics related to risk of the metabolic syndrome? A review of the literature. Ann Behav Med 2007, 34(3):240-52.

7. Spielberger CD: State-Trait Anger Expression Inventory Odessa, FL: Psychological Assessment Resource Inc 1999.

8. Kassinove H: Anger disorders: Definition, diagnosis, and treatment Washington, DC: Taylor \& Francis 1995.

9. Bleil ME, McCaffery JM, Muldoon MF, Sutton-Tyrrell K, Manuck SB: Angerrelated personality traits and carotid artery atherosclerosis in untreated hypertensive men. Psychosom Med 2004, 66(5):633-9.

10. Narita K, Murata T, Takahashi T, Hamada T, Kosaka H, Yoshida H, Wada Y: The association between anger-related personality trait and cardiac autonomic response abnormalities in elderly subjects. Eur Arch Psychiatry Clin Neurosci 2007, 257(6):325-9.

11. Merjonen P, Pulkki-Raback L, Puttonen S, Keskivaara P, Juonala M, Telama R, Viikari J, Raitakari OT, Keltikangas-Jarvinen L: Anger is associated with subclinical atherosclerosis in low SES but not in higher SES men and women. The Cardiovascular Risk in Young Finns Study. J Behav Med 2008, 31:35-44.

12. Holt-Lunstad J, Smith TW, Uchino BN: Can hostility interfere with the health benefits of giving and receiving social support? The impact of cynical hostility on cardiovascular reactivity during social support interactions among friends. Ann Behav Med 2008, 35(3):319-30.

13. Ravaja N, Kauppinen T, Keltikangas-Jarvinen L: Relationships between hostility and physiological coronary heart disease risk factors in young adults: the moderating influence of depressive tendencies. Psychol Med 2000, 30(2):381-93.

14. Boyle SH, Williams RB, Mark DB, Brummett BH, Siegler IC, Helms MJ, Barefoot JC: Hostility as a predictor of survival in patients with coronary artery disease. Psychosom Med 2004, 66:629-632.

15. Olson MB, Krantz DS, Kelsey SF, Pepine CJ, Sopko G, Handberg E, Rogers WJ, Gierach GL, McClure CK, Merz CN, WISE Study Group: Hostility scores are associated with increased risk of cardiovascular events in women undergoing coronary angiography: a report from the NHLBISponsored WISE Study. Psychosom Med 2005, 76:546-552.

16. Everson SA, Kauhanen J, Kaplan GA, Goldberg DE, Julkunen J, Tuomilehto J, Salonen JT: Hostility and increased risk of mortality and acute myocardial infarction: The mediating role of behavioral risk factors. Am J Epidemiol 1997, 146:142-152

17. Siegman AW, Townsend ST, Blumenthal RS, Sorkin JD, Civelek AC: Dimensions of anger and CHD in men and women: self-ratings versus spouse ratings. J Behav Med 1998, 21(4):315-36.

18. Krantz DS, Olson MB, Francis JL, Phankao C, Bairey Merz CN, Sopko G, Vido DA, Shaw LJ, Sheps DS, Pepine CJ, Matthews KA: Anger, hostility, and cardiac symptoms in women with suspected coronary artery disease: the Women's Ischemia Syndrome Evaluation (WISE) Study. J Womens Health 2006, 15(10):1214-23.

19. Shephard RJ, Franklin B: Changes in the quality of life: a major goal of cardiac rehabilitation. J Cardiopulm Rehabil 2001, 21(4):189-200.

20. Oldridge $\mathrm{N}$ : Assessing health-related quality of life: is it important when evaluating the effectiveness of cardiac rehabilitation? J Cardiopulm Rehabil 2003, 23(1):26-8. 
21. Julkunen J, Ahlstrom R: Hostility, anger, and sense of coherence as predictors of health-related quality of life. Results of an ASCOT substudy. J Psychosom Res 2006, 61(1):33-9.

22. Shen BJ, Myers HF, McCreary CP: Psychosocial predictors of cardiac rehabilitation quality-of-life outcomes. J Psychosom Res 2006, 60(1):3-11.

23. Shen BJ, McCreary CP, Myers HF: Independent and mediated contributions of personality, coping, social support, and depressive symptoms to physical functioning outcome among patients in cardiac rehabilitation. J Behav Med 2004, 27(1):39-62.

24. Joosten EA, Fuentes-Merillas $L$, de Weert GH, Sensky T, van der Staak $C P$, de Jong CA: Systematic review of the effects of shared decision-making on patient satisfaction, treatment adherence and health status. Psychother Psychosom 2008, 77(4):219-26.

25. O'Connor AM, Bennett CL, Stacey D, Barry M, Col NF, Eden KB, Entwistle VA, Fiset V, Holmes-Rovner M, Khangura S, Llewellyn-Thomas H, Rovner D: Decision aids for people facing health treatment or screening decisions. Cochrane Database of Syst Rev 2009, 3.

26. Zachariae $R$, Pedersen $C G$, Jensen $A B$, Ehrnrooth $E$, Rossen $P B$, von der Maase $\mathrm{H}$ : Association of perceived physician communication style with patient satisfaction, distress, cancer-related self-efficacy, and perceived control over the disease. Br J Cancer 2003, 88:658-665.

27. Stewart M, Brown JB, Donner A, McWhinney IR, Oates J, Weston WW, Jordan J: The impact of patient-centered care on outcomes. J Fam Pract 2000, 49:796-804.

28. Lee $Y Y$, Lin JL: The effects of trust in physician on self-efficacy, adherence and diabetes outcomes. Soc Sci Med 2009, 68:1060-1068.

29. Le Grande MR, Elliot PC, Murphy BM, Worcester MUC, Higgins RO, Ernest CS, Goble AJ: Health related quality of life trajectories and predictors following coronary artery bypass surgery. Health Qual Life Outcomes 2006, 4.

30. Müller-Nordhorn J, Kulig M, Binting S, Völler H, Gohlke H, Linde K, Willich SN: Change in quality of life in the year following cardiac rehabilitation. Qual Life Res 2004, 13:399-410.

31. Veenstra M, Pettersen KI, Rollag A, Stavem K: Association of changes in health-related quality of life in coronary heart disease with coronary procedures and sociodemographic characteristics. Health Qual Life Outcome 2004, 2:56.

32. Oldridge N, Gottlieb M, Guyatt G, Jones N, Streiner D, Feeny D: Predictors of healthrelated quality of life with cardiac rehabilitation after acute myocardial infarction. J Cardiopulm Rehabil 1998, 18:95-103.

33. van Eck JW, van Hemel NM, van den BA, Taks W, Grobbee DE, Moons KG: Predictors of improved quality of life 1 year after pacemaker implantation. Am Heart J 2008, 156(3):491-7.

34. Daly CA, De Stavola B, Sendon JLL, Tavazzi L, Boersma E, Clemens F, Danchin N, Delahaye F, Gitt A, Julian D, Mulcahy D, Ruzyllo W, Thygesen K, Verheugt F, Fox KM, on behalf of the Euro Heart Survey Investigators: Predicting prognosis in stable angina-results from the Euro heart survey of stable angina: prospective observational study. BMJ 2006, 332:262-267.

35. Makoul G, Clayman ML: An integrative model of shared decision making in medical encounters. Patient Educ Couns 2006, 60:301-312.

36. Karoff M, Held K, Bjarnason-Wehrens B: Cardiac rehabilitation in Germany. Eur J Cardiovasc Prev Rehabil 2007, 14:18-27.

37. Ware JE, Kosinski M, Keller SD: A 12-item short-form health survey: construction of scales and preliminary tests of reliability and validity. Med Care 1996, 34:220-233.

38. Höfer S, Lim LLY, Guyatt G, Oldridge N: The MacNew Heart Disesease health-related quality of life instrument: A summary. Health Qual Life Outcome 2004, 2:3.

39. Spertus JA, Winder JA, Dewhurst TA, Deyo RA, Prodzinski J, McDonell M, Fihn SD: Development and evaluation of the Seattle Angina Questionnaire: a new functional status measure for coronary artery disease. J Am Coll Cardiol 1995, 25:333-341.

40. Lerman CE, Brody DS, Caputo GC, Smith DG, Lazaro CG, Wolfson HG: Patients' Perceived Involvement in Care Scale: Relationship to attitudes about illness and medical care. J Gen Intern Med 1990, 5:29-33.

41. Anderson LA, Dedrick RF: Development of the trust in physician scale: a measure to assess interpersonal trust in patient-physician relationships. Psychol Rep 1990, 67:1091-1100.

42. Graham JR: MMPI-2: Assessing personality and psychopathology New York, NY: Oxford University Press 2000.
43. Maurischat C, Morfeld M, Kohlmann T, Bullinger M: Lebensqualität: Nützlichkeit und Psychometrie des Health Survey SF-36/SF-12 in der medizinischen Rehabilitation Lengerich: Pabst 2004.

44. Höfer S, Benzer W, Schüßler G, von Steinbüchel N, Oldridge N: Healthrelated quality of life in patients with coronary artery disease treated for angina: Validity and reliability of German translations of two specific questionnaires. Qual Life Res 2003, 12:199-212.

45. Graham JW: Missing data analysis: Making it work in the real world. Annu Rev Psychol 2009, 60:549-576.

46. Rubin DB: Multiple imputation for nonresponse in surveys New York: Wiley 1987.

47. Schafer JL: NORM: Multiple imputation of incomplete multivariate data under a normal model, version 2.03, software for Windows 95/98/NT 1999 [http:// www.stat.psu.edu/ jls/misoftwa.html].

48. Menard SW: Applied logistic regression analysis Thousand Oaks, CA: Sage 2002.

49. PASW Statistics - SPSS 17 Chicago, IL: SPSS, Inc 2008.

50. Cohen J: Statistical power analysis for the behavioral sciences New York: Academic Press, 21988.

51. Cooper RS: Social inequality, ethnicity and cardiovascular disease. Int J Epidemiol 2001, 30(Suppl 1):S48-52.

52. Morgan MW, Deber RB, Llewellyn-Thomas HA, Gladstone P, Cusimano RJ, O'Rourke K, Tomlinson G, Detsky AS: Randomized, controlled trial of an interactive videodisc decision aid for patients with ischemic heart disease. J Gen Intern Med 2000, 15(10):685-93.

53. Montgomery AA, Fahey T, Peters TJ: A factorial randomised controlled trial of decision analysis and an information video plus leaflet for newly diagnosed hypertensive patients. Br J Gen Pract 2003, 53(491):446-53.

54. Naik $A D$, Kallen MA, Walker A, Street RL Jr: Improving hypertension control in diabetes mellitus - The effects of collaborative and proactive health communication. Health Serv Res 2008, 117:1361-1368.

55. Zolnierek KBH, DiMatteo MR: Physician communication and patient adherence to treatment: A meta-analysis. Med Care 2009, 47:826-834.

56. Cegala DJ, Post DM: On addressing racial and ethnic health disparities: The potential role of patient communication skills interventions. Am Behav Sci 2006, 49(6):853-867.

57. Harrington J, Noble LM, Newman SP: Improving patients' communication with doctors: a systematic review of intervention studies. Patient Educ Couns 2004, 52(1):7-16

58. Moret L, Nguyen JM, Pillet N, Falissard B, Lombrail P, Gasquet I: Improvement of psychometric properties of a scale measuring inpatient satisfaction with care: a better response rate and a reduction of the ceiling effect. BMC Health Services Research 2007, 7:197.

59. Moore JC, Stinson LL, Welniak EJ: Income measurement error in surveys: A review. J Official Statistics 2000, 16:331-361.

60. Kim S, Egerter S, Cubbin C, Takahashi ER, Braveman P: Potential implications of missing income data in population-based surveys: an example from a postpartum survey in California. Public Health Rep 2007, 122(6):753-63.

61. Farin E, Dudeck A, Meffert C, Glattacker M, Jäckel WH, Beckmann U, Böwering $L$ : Qualitätssicherung in der ambulanten medizinischen Rehabilitation: Konzeption und Ergebnisse eines Pilotprojekts zur Entwicklung eines Qualitätssicherungsprogramms für die Indikationsbereiche Muskuloskeletale und Kardiologische Erkrankungen. Rehabilitation 2007, 46:198-211.

62. Hevey D, McGee HM, Horgan J: Relationship of initial level of distress to changes in health-related quality of life during cardiac rehabilitation or usual care. Psychosom Med 2007, 69(8):793-7.

63. Frasure-Smith N, Lesperance F: Depression and other psychological risks following myocardial infarction. Arch Gen Psychiatry 2003, 60(6):627-36.

64. Moumjid N, Gafni A, Bremond A, Carrere MO: Shared decision making in the medical encounter: are we all talking about the same thing? Med Decis Making 2007, 27(5):539-46.

65. Legare F, Stacey D, Graham ID, Elwyn G, Pluye P, Gagnon MP, Frosch D, Harrison MB, Kryworuchko J, Pouliot S, Desroches S: Advancing theories, models and measurement for an interprofessional approach to shared decision making in primary care: a study protocol. BMC Health Serv Res 2008, 8:2.

66. Greenland S: Principles of multilevel modelling. Int J Epidemiol 2000, 29:158-167. 
67. Singh-Manoux A, Marmot MG, Adler NE: Does subjective social status predict health and change in health status better than objective status? Psychosom Med 2005, 67(6):855-61.

68. Doty DH, Glick WH: Common methods bias: Does common methods variance really bias results? Organizational Res Methods 1998, 1:374-406.

doi:10.1186/1477-7525-8-100

Cite this article as: Farin and Meder: Personality and the physicianpatient relationship as predictors of quality of life of cardiac patients after rehabilitation. Health and Quality of Life Outcomes 2010 8:100.

Submit your next manuscript to BioMed Central and take full advantage of:

- Convenient online submission

- Thorough peer review

- No space constraints or color figure charges

- Immediate publication on acceptance

- Inclusion in PubMed, CAS, Scopus and Google Scholar

- Research which is freely available for redistribution

Submit your manuscript at www.biomedcentral.com/submit
C Biomed Central 